\title{
Christie Davies and substantive reality
}

\author{
Victor Raskin \\ Purdue University \\ vraskin@purdue.edu
}

I met Christie in the summer of 1979 in Los Angeles at what became remembered as The Second International Conference on Humour. It was attended by thousands of people, most of them South Californian shrinks who wanted to tell their favourite joke and could easily afford a steep (tax-deductible) registration fee for the pleasure. There were very few humour researchers there, and these two of them found each other and started a mutual adoration pact that lasted for decades.

That was my first humour conference because I managed to miss the first one in Cardiff back in 1976, even though I was on the island at the time, attending the first of the many much more stupid British Artificial Intelligence conferences to follow. In doing so, I fatefully avoided a much heavier overlap with arousal-resolution psychologists of humour who were the more serious researchers there. At the 1979 conference, I destroyed their hegemony and established linguistics as the target of hatred for European humour researchers. (Yes, I know that this is the European journal!)

I think Christie had just heard my talk that was kindly presented by Don Nilsen as sensational, but this is not what we talked about for several hours on a circular bench around some artefact in the enormous lobby of the hotel. He discovered that I knew a lot-actually, all - of Soviet jokes, and I ended up reciting them to him. He carefully wrote them down, sometimes commenting that he heard one in a different version-several, apparently from Emil Draitser, who had published a few dozen in English translation or maybe bilingually. Surprisingly, I did not feel diminished by the role of an informant, and the reason for that was that this was an amazingly thoughtful process.

I provided the refined Moscow-cultural-elite versions, and they differed from what Christie had encountered before in most interesting ways. The other versions were often longer, had worse synonyms and strange paraphrases. Back in Moscow, only six years earlier, the correct versions were like passwords that made the tellers trustworthy and acceptable for that elite, which excluded government employees and their children and included writers, painters, some journalists and their children, many of them Jewish. What irritated the inpeople in other versions was words that jarred the ear but also there was something much more important that fascinated me as Christie and I continued because I was understanding something that was not clear to me before: the wrong versions did not lead to the scripts directly.

That was the first time when a conversation with Christie crystalized something in my mind, and then it happened almost every time we met and talked, which was barely once a 
year, and we missed several opportunities. Christie and I did not talk about the scripts much in that conversation, and yet the whole conversation was somehow about them. Jumping a couple of decades forward, in 2000, Salvatore Attardo, my former Ph.D. advisee, used his invited participation in some jubilee to "accuse" me of being an essentialist. I immediately admitted that, but I had never thought of myself in these terms before.

What brought Christie and me together in that first conversation and throughout the 38 years that followed was that he was an essentialist himself. It is not that his research was explicitly so but it was important to him that jokes had substances, and that underlies all of his work, including his highest achievements relating to joke comparison: the sociological proof that American Polish jokes were not rooted in the immigration history; the similarity between the Jewish and Scottish jokes explained by the high turnover of Jewish and Church of Scotland congregations; and the amazing fact that, in the 1990s, many Soviet jokes were published in England and sold well but they were never transferred to English material because of the ingrained difference between Western and Russian political realities. None of these things were easy to discover and to assert without utter belief that jokes had content, substance, terra firma.

Christie became an immediate adherent of my Script-based Semantic Theory of Humour, and defended it against inept criticism by mostly European scholars exactly on the point. I was the first open proponent of humour essentialism, and it gave him the firm foundation for his own major discoveries. He did not have to do this essentialist research, but it was important to him that somebody he trusted did. I never had a chance to discuss it with him, but I strongly suspect that the main reason for that trust that I was a mathematician, and my scripts that defined the essence of jokes were mathematical objects. It took a talent to recognize that in the somewhat loosely defined objects-deliberately so for a "soft" audience - that are still undergoing a tightening-up treatment for computerization several decades later.

The scripts of my first Script-based Semantic Theory of Humour (SSTH) were presented softly but they were not. They were "intuitively clear," and that is always based on objective reality. With the exception of one or two holdouts, nobody ever argued that the infamous doctor joke was based on the opposition of the doctor's wife letting the patient in to wait for the doctor and her letting him in for illicit sex while her husband was away. There was never any doubt in my mind that the scripts were elements of cognition shared by all people and triggered by a text in natural language. But it was not until the current version of my evolving theory, the Ontological Semantic Theory of Humour (OSTH) that it was firmed up, and the important cognitive prejudices had to be cleared up on the way.

I have always wanted to come up with a linguistic theory of humour, and linguistics was always mathematical to me. I did not understand that I was trying to detect and describe the patterns of humour until, at the age of 17, my future (and current) wife Marina, who hated my compulsive humourism, responded to a joke of mine by asking angrily if it was Formula 17. I realized right away that the joke was formulaic and that all of my jokes were: I recycled the same patterns over and over again, sometimes mixing and mingling them.

I immediately tried to apply structural linguistics to humour. I knew very little of it first but, as I learned all of it, what became clear was that the syntax it delivered was not enoughin fact, it did not touch anything in humour. Chomsky's generative grammars were no better. Linguistics simply did not have what humour needed. My career in computational linguistics has moved me to developing computational semantics, and as I made progress, I could apply it more and more to humour - in fact, test it on humour.

By the mid-70s, I graduated to scripts, structure chunks of information, which clearly mattered more than the messy semantics of lexical items. From Israel, I ran a two-round Round Table on Semantics in Mario Alinei's Quaderni di Semantica, and the idea of scripts was accepted enough to encourage me to put together a six-page double-column single-spaced 
item on semantic mechanisms of humour for a student-run but prestigious and competitive annual meeting of the Berkeley Linguistic Society. It went reasonably well, mostly as a curious oddity there, probably because of the growing schism, centrally displayed there, between the militant feminist linguist Robin Lakoff and her former best student Deborah Tannen, who had escaped her first marriage to a sexist Greek, returned to Berkeley for a Ph.D., and had just defended her dissertation. Deborah already sounded conciliatory towards men, which her first bestseller made clear some 12 years later, while Robin believed that men were all to be castrated and killed (or maybe more mercifully, killed and castrated).

The episode brought me a good friendship with Tannen who was a sociolinguist and who also immediately accepted my approach to humour as serious and promising and cited it as such in her publications (she also urged me to write a trade book on it and make millions like herself). So she was a precursor of Christie's but, unlike him and like me, she had been introduced to patterns in her education, following the ideas of Diane Hoffman and John Gumperz. Then I presented a version of the paper, easier on linguistic formalism, to the session organized and coordinated by Don Nilsen at that humour conference, where Christie and I met, and the presentation was sensational.

Let us now look more closely on what makes the scripts intuitively clear and where it leads in semantics. What humans possess and add to the meaning of every sentence is the shared knowledge of the world. We have concepts for every known object and event in the world as well as the multiple properties that bind them together. We have a pretty universal knowledge of how these objects interact with each other. And we have familiarity with commonly occurring sequences of interactions that constitute scripts. We are so familiar with them that we do not have to spell them out and can recall the whole script by verbalizing only a few of the constituents in our communications.

In the joke, we realize that the patient had to get to the doctor's office and ask for admission, then he asked about the doctor's availability and expected to be admitted and be seen or asked to wait. What actually happened disrupted the normal script because he was told that the doctor was away, and he was invited in. The first script could be saved by the doctor's wife adding that the doctor would be back soon enough for the patient to wait (the normal script even has quantitative limits: half an hour is okay, but two hours stretches it). When no normalizing explanation is forthcoming, the last sentence becomes part of a different script, for which the patient and the hearers of the joke have to find the initial steps, and they assemble them from his whisper that the doctor's wife misinterprets as intimate, and the fact that she is young and pretty. (The joke is unabashedly sexy because it comes from the American rural 1930s.)

The initial knowledge of the world is contained in the ontology in my ontological semantics. It does contain all the object, event, and properties that a human knows. They make is possible to assemble the scripts. The first researchers who developed the semantics of the sentence in 1963, Jerrold Katz and Jerry A. Fodor declared that they were unable to represent all human knowledge of the world, and as a result, they refused to disambiguate the sentence Our store sells alligator shoes as meaning shoes for alligators or shoes made of alligator skin. My point is that we all know that alligators do not wear shoes unlike horses whom we shod.

We use our knowledge of the world to disambiguate sentences and to complement their meanings, and we do it unconsciously, which makes it rather difficult to account for. Ontological semantics was first developed as a formal theory for computational semantics, and we do develop computational humour. It is the computer's total lack of the knowledge of the world that makes it virtually impossible for it to assemble the understanding of natural language text out of the recorded dictionary meanings of lexical items. This has made it necessary to formalize the complete theory of our knowledge of the world, and we are in the process of its incremental implementation. 
This makes this activity always incomplete, limited to feasibility in limited domains if science and technology and with limited grain size. However, it is always easy, feasible, and cheap to adjust the ontology to a new domain or a more refined level of detailisation. We no longer fear unlimited tasks. We no longer swear by parsimony. And we forfeit the once ubiquitous first-order predicate logic because it does not apply to natural language. And the moment somebody attempts to sell you machine or deep learning, big data, or their cloud for your semantic needs, smile and run! Or use one of Christie's choice unprintable in many languages. 